\title{
A Novel Niosomal Combination of Selenium Coupled with Glucantime against Leishmania tropica
}

\author{
Mahshid Mostafavi', Payam Khazaeli'i*, Iraj Sharifi', Saeedeh Farajzadeh³, Hamid Sharifi', Alireza Keyhani', \\ Maryam Hakimi Parizi', Sina Kakooei' \\ ${ }^{1}$ Leishmaniasis Research Center, Kerman University of Medical Sciences, Kerman, Iran; '2Department of Pharmaceutics, Faculty of Pharmacy, \\ Kerman University of Medical Sciences, Kerman, Iran; ${ }^{3}$ Department of Pediatric Dermatology, Kerman University of Medical Sciences, Kerman, Iran; \\ ${ }^{4}$ HIV/STI Surveillance Research Center, and WHO Collaborating Center for HIV Surveillance, Institute for Futures Studies in Health, Kerman \\ University of Medical Sciences, Kerman, Iran
}

\begin{abstract}
There is no effective treatment modality available against different forms of leishmaniasis. Therefore, the aim of this study was to improve the penetration and efficacy of selenium and glucantime coupled with niosomes and compared them with their simple forms alone on in vitro susceptibility assays. In this study, the niosomal formulations of selenium and in combination with glucantime were prepared. The size and morphology of the niosomal formulations were characterized and the effectivity of the new formulation was also evaluated using in vitro MTT assay, intra-macrophage model, and gene expression profile. From the results obtained, no cytotoxicity effect was observed for niosomal and simple forms of drugs, as alone or in combination. Niosomal formulations of the drugs significantly showed more inhibitory effects $(P \leq 0.001)$ than the simple drugs when the selectivity index was considered. The gene expression levels of Interleukin (IL-10) significantly decreased, while the level of IL-12 and metacaspase significantly increased $(P \leq 0.001)$. The results of the present study showed that selenium plus glucantime niosome possess a potent anti-leishmanial effect and enhanced their lethal activity as evidenced by the in vitro experiments.
\end{abstract}

Key words: Leishmania tropica, selenium, glucantime, niosomes, anti-leishmanial effect, cytokine

\section{INTRODUCTION}

Leishmaniasis is a neglected disease distributed in more than 98 countries in the world and it has been reported that almost 0.7-1.2 million cases of cutaneous leishmaniasis (CL) occur each year $[1,2]$. Two common forms of $\mathrm{CL}$, such as anthroponotic cutaneous leishmaniasis (ACL) caused by Leishmania tropica (L. tropica) and zoonotic CL (ZCL) caused by $L$. major, are present in Iran [3-6].

The clinical manifestations of leishmaniasis are of various form of a self-limiting lesion to damaging mucocutaneous lesions, which depend on the Leishmanias species and the type of immune response to the disease [7]. Antimonial drugs $(\mathrm{SbV})$ are considered as the first line of drugs for all forms of Leishmania treatment [8]. However, their efficacy is decreased

- Received 27 October 2018, revised 16 January 2019, accepted 22 January 2019.

*Corresponding author (Khazaeli.payam97@gmail.com)

(c) 2019, Korean Society for Parasitology and Tropical Medicine

This is an Open Access article distributed under the terms of the Creative Commons Attribution Non-Commercial License (http://creativecommons.org/licenses/by-nc/4.0) which permits unrestricted non-commercial use, distribution, and reproduction in any

medium, provided the original work is properly cited. depending on the Leishmanias species and geographical regions [9].

Additionally, all current treatments have limitations derived from their high cost, route of administration, drug resistance, long duration of treatment and especially, serious side effects such as nephrotoxicity, hypokalemia, hepatic and pancreatic toxicity, hypotension and dysglycemia among others. Therefore, there is an urgent need for the development of innovative treatment modalities against leishmaniasis that are safe, inexpensive and easily available to the patients. Furthermore, the discovery of new lead compounds for this disease is a pressing concern for global health programs.

Selenium (Se) is an essential element for human health including antiviral activities, cancer prevention, antioxidant and anti-inflammatory effects [10]. Selenium ions ameliorate the immune response of hosts against various species of viral antigen and bacteria [11]. Several studies have demonstrated appropriate efficacy of selenium nanoparticles against $L$. major, $L$. tropica, and L. infantum [12-14].

Vesicular drug delivery is one of the approaches that encapsulate drug. Examples include niosomes, transferosomes, lipo- 
somes, provesicles and pharmacosomes. The benefits of niosomes and liposomes over other conventional forms are their action as a drug reservoir owing to their particulate nature. Niosomes have more stable structures than liposomes even in the emulsified form [15].

Niosomes are drug carriers with a bilayer structure in an aqueous phase which are formed by nonionic surfactants and cholesterol. They exhibit high stability, long shelf life and facilitate the delivery of drug at target site in a sustained mode. In addition, as a novel carrier of drugs, they are biocompatible, biodegradable and nonimmunogenic [16].

In this study, the niosomal formulation of selenium and in combination with glucantime were prepared and their activity was assessed using in vitro MTT assay, intra-macrophage mod$\mathrm{el}$, and gene expression profile. The size and morphology of niosomal formulation were characterized. The aim of this study was to improve the penetration and effectivity of selenium and glucantime coupled with niosomes and compared with these drugs alone by in vitro susceptibility assays.

\section{MATERIALS AND METHODS}

\section{Preparation of drug}

Glucantime (Sanofi-Aventis, Paris, France) and selenium dioxide 99.9\% (SIGMA-ALDRICH/Lot 079K368021) were purchased from commercial sources in Iran. Glucantime and selenium were diluted in Roswell Park Memorial Institute medium (RPMI-1640) (Biosera, Nuaille, France) to prepare serial dilutions $(12.5,25,50,100$, and $200 \mu \mathrm{g} / \mathrm{ml})$ [17] freshly before performing each test.

For combination of glucantime and selenium, first and foremost, the concentrations of selenium remained constant, while glucantime was used in increasing order of concentrations $(50,100$, and $200 \mu \mathrm{g} / \mathrm{ml})$. Secondly, the concentrations of Glucantime were constant and selenium was decreasing in order of concentrations.

In the niosomal combination of glucantime and selenium, at first, the concentrations were based on selenium (selenium plus glucantime niosome) and thereafter, the serial dilutions were based on glucantime (glucantime plus selenium niosome).

\section{Preparation of niosome}

Selenium niosome and selenium plus glucantime niosome were prepared using film hydration method [18]. In a round bottom flask, Span $40(5 \mathrm{~g} / 50 \mathrm{ml})$, Tween $40(2.5 \mathrm{~g} / 50 \mathrm{ml})$ and cholesterol $(2.5 \mathrm{~g} / 50 \mathrm{ml})$ were dissolved in chloroform. The chloroform was evaporated in a rotary evaporator at $60^{\circ} \mathrm{C}$ and $4 \mathrm{~g}$ for $30 \mathrm{~min}$. The thin layer of film was left to cover the inner walls of the flask. The hydration of obtained film was performed by $5 \mathrm{ml}$ deionized water, in which selenium (1\%) and also combination of selenium (1\%) and glucantime (1.5\%) were dissolved at $55^{\circ} \mathrm{C}$ for $1 \mathrm{hr}$. The obtained niosomes were solicited for $30 \mathrm{~min}$ by bath sonication. To complete hydration, niosamal formulation of each drug were kept at room temperature $\left(24 \pm 1^{\circ} \mathrm{C}\right)$ for $24 \mathrm{hr}$.

\section{Characterization of niosomes}

The size dispensation of the niosomes was determined using laser light diffraction method by Malvern apparatus (Malvern Mastersizer X, Malvern, UK). The morphology of niosomal formulations was surveyed using camera that was attached to a light microscope (Zeiss, Oberkochen, Germany), equipped with a computer controlled image analysis system.

\section{Leishmania parasite culture}

L. tropica standard strain MHOM/IR/75/Mash2 was cultured in Novy-MacNeal-Nicolle (NNN) medium, incubated at $24^{\circ} \mathrm{C} \pm 1$ and subcultured in RPMI-1640 (Biosera) supplemented with $15 \%$ heat inactivated (at $56^{\circ} \mathrm{C}$ for $30 \mathrm{~min}$ ) fetal bovine serum (FBS, Gibco, Carlsbad, California, USA), 1\% penesterep (Life Technology, Carlsbad, California, USA).

\section{Murine macrophage cell line culture}

J774A.1 ATCC ${ }^{\circledR}$ TIB- $67^{\mathrm{TM}}$ was purchased from the Pasteur Institute of Iran (Tehran, Iran) and cultured in DMEM medium supplemented with $10 \%$ inactivated FBS, $0.5 \%$ penicillin (Sigma, Poole, UK), 0.5\% streptomycin (Sigma) and incubated at $37^{\circ} \mathrm{C}$ with $5 \% \mathrm{CO}_{2}$.

\section{Cytotoxicity of drugs on murine macrophage cells}

Prior to the tests on L. tropica extracellular promastigote and intracellular amastigote, the cytotoxicity concentrations of glucantime, selenium niosome, selenium plus glucantime, selenium plus glucantime niosome and glucantime plus selenium niosome were determined on J774 cells.

Murine macrophage cells $\left(5 \times 10^{4}\right)$ were cultured in 96 wellmicroplate and incubated at $37^{\circ} \mathrm{C}$ with $5 \% \mathrm{CO}_{2}$ for $2 \mathrm{hr}$. After the incubation period, different concentrations of each drug $(12.5-200 \mu \mathrm{g} / \mathrm{ml})$ were added to each well of the 96-wellmicroplate and incubated for $72 \mathrm{hr}$. Thereafter, $10 \mu \mathrm{l}$ MTT (3-[4, 
Table 1. Primers which were used for real-time PCR

\begin{tabular}{|c|c|c|c|c|}
\hline Primers & Gene & Forward Sequence $\left(5^{\prime}-3^{\prime}\right)$ & Reverse Sequence $\left(5^{\prime}-3^{\prime}\right)$ & $\begin{array}{l}\text { Product } \\
\text { size (bp) }\end{array}$ \\
\hline $\begin{array}{l}\text { Macrophages } \\
\text { murine cells }\end{array}$ & $\begin{array}{l}\text { IL-12 P40 } \\
\text { IL-10 } \\
\text { GAPDH }\end{array}$ & $\begin{array}{l}\text { CTGGAGCACTCCCCATTCCTA } \\
\text { CTTACTGACTGGCATGAGGATCA } \\
\text { AGCTTCGGCACATATTTCATCTG }\end{array}$ & $\begin{array}{l}\text { GCAGACATTCCCGCCTTG } \\
\text { GCAGCTCTAGGAGCATGTGC } \\
\text { CGTTCACTCCCATGACAAACA }\end{array}$ & $\begin{array}{r}160 \\
101 \\
89\end{array}$ \\
\hline $\begin{array}{l}\text { Promastigotes of } \\
\text { L. tropica }\end{array}$ & $\begin{array}{l}\text { Metacaspase } \\
\text { RPS18 Ribosomal protein (S18) }\end{array}$ & $\begin{array}{l}\text { CAGCAACAATTCCTGGCGATA } \\
\text { GTTGAGGTGCGTGGTCTGTC }\end{array}$ & $\begin{array}{l}\text { AAGTTGAAGTAAAAGGAGACAATTTGG } \\
\text { TGCAGGTTGCTCAGGAGCTT }\end{array}$ & $\begin{array}{l}140 \\
166\end{array}$ \\
\hline
\end{tabular}

5-Dimethylthiazol-2-yl]-2, 5-diphenyltetrazolium bromide; Thiazolyl blue) (Sigma Aldrich, St. Louis, Missouri, USA) (5 $\mathrm{mg} / \mathrm{ml}$ ) was added to each well of the microplate and incubated for $3 \mathrm{hr}$. The wells with medium and parasite without any drugs were considered as untreated control. Thereafter, $100 \mu \mathrm{l}$ Dimethyl sulfoxide (DMSO) (Merck, Darmstadt, Germany) were added for dissolving formazan crystals and incubated at room temperature in the dark for $1 \mathrm{hr}$. Optical density (OD) was read at $490 \mathrm{~nm}$ using ELISA-reader (Bio Tek-ELX800, Winooski, Vermont, USA). The 50\% cytotoxicity concentration $\left(\mathrm{CC}_{50}\right)$ was determined by probit test in SPSS software version 20 (SPSS Inc., Chicago, Illinois, USA).

\section{Extra-cellular promastigote assay}

Promastigotes $\left(1 \times 10^{5}\right)$ were cultured at log phase in 96-well microliter plate and $10 \mu \mathrm{l}$ of different concentrations of all drugs with $60 \mu \mathrm{l}$ RPMI-1640 were added to each well and incubated at $24^{\circ} \mathrm{C} \pm 1$ for $72 \mathrm{hr}$. Promastigote in medium without any drug was considered as the untreated control, while medium with no promastigote was used as blank. All experiments were performed 3 times. Ten $\mu$ of MTT solution in RPMI-1640 (no phenol red) was added to each well and incubated at $24 \pm 1^{\circ} \mathrm{C}$ for 4 hr. The reaction was terminated by DMSO and read using an ELISA reader at $490 \mathrm{~nm}$. The 50\% inhibitory concentration (IC50) was assessed by probit test using SPSS software.

\section{Intra-cellular amastigote assay}

Cells ( $1 \times 10^{5}$ cells) of the $\mathrm{J774}$ murine macrophage cell line were cultured on the slides in sterile plates and incubated at $37^{\circ} \mathrm{C}$, with $5 \% \mathrm{CO}_{2}$ for $2 \mathrm{hr}$. The promastigotes $\left(1 \times 10^{6}\right)$ in the stationary phase were added to each slide and then incubated for $24 \mathrm{hr}$. After the incubation period, different concentrations of all drugs were added to the slides and incubated at $37^{\circ} \mathrm{C}$ for $72 \mathrm{hr}$. At the end, the slides were dried, fixed with methanol, and stained by Giemsa for evaluation under a light microscope. The effectiveness of each drug was evaluated by the mean number of amastigotes in 100 macrophages. Every ex- periment was performed in triplicate.

\section{Quantitative real-time PCR (qPCR)}

RNeasy ${ }^{\circledR}$ mini kit (Qiagen, Chatsworth, California, USA) was used for the extraction of RNA according to the manufacturer's protocol. Nanodrop ND-1000 spectrophotometer (Thermo Scientific, Wilmington, Delaware, USA) was used for the determination of quantity and purity of each sample. Then, cDNA was synthesized using the TaKaRa Prime Script ${ }^{\mathrm{TM}}$ RT reagent kits (Takara Clontech, California, USA). Glyceraldehyde 3-phosphate dehydrogenase (GAPDH) [19,20] was used as reference gene for gene expression of IL-12 and IL-10 in murine macrophage cells (J-774) and RPS18 Ribosomal protein (S18) $[21,22]$ for gene expression of metacaspase in Leishmania (Table 1). Quantitative RT-PCR of target cDNA was run on a Rotorgene 3000 cycler system (Corbett Research, Sydney, Australia). The PCR reaction for mRNA detection was carried out in reaction volumes $(10 \mu \mathrm{l})$ including $5 \mu \mathrm{l}$ 2X SYBR Green Supermix (SYBR ${ }^{\circledR}$ Premix Ex Taq ${ }^{\mathrm{TM}}$, Takara Clontech), $250 \mathrm{nmol}$ forward and $250 \mathrm{nmol}$ reverse primer, and $1 \mu \mathrm{l}$ cDNA diluted in RNase-free water. PCR reactions were performed in duplicates and results were normalized to the levels of GAPDH and S18 genes as reference genes. To calculate the relative value of the expression level, $2^{-\Delta \Delta \mathrm{Ct}}$ method was used as a relative quantification approach for qPCR data analysis.

\section{Statistical analyses}

Data analysis was done using SPSS software version 20. ANOVA and independed $t$-test were used to determine the significant relationship between the treatment groups, also $\mathrm{IC}_{50}$ and $\mathrm{CC}_{50}$ were calculated by probit test. The mean $2^{-\Delta \mathrm{Ct}}$ for treatment and the mean $2^{-\Delta \mathrm{Ct}}$ for control for each cytokine were compared using GRAPHPAD PRISM 6 (GraphPad Software Inc., San Diego, California, USA). $P<0.05$ was considered as significant.

The Minimum Standards of Reporting Checklist contains details of the experimental design, and statistics, and resources used in this study. 


\section{RESULTS}

\section{Niosome preparation}

In the first step, 3 different formulations for each drug were prepared and then the determination of the morphology and size was carried out. Selection of the best formulation procedure due to medium spherical multi-layer vesicles (Fig. 1) with sizes of $9.75 \pm 0.35$ and $5.4 \pm 0.14 \mu \mathrm{m}$ for selenium noisome and selenium plus glucantime niosome was accomplished, respectively.

\section{Cytotoxicity analysis}

In the investigation of the cytotoxicity of drugs, various concentrations of these drugs and niosomal formulation of them $(12.5-200 \mu \mathrm{g} / \mathrm{ml})$ were applied on macrophage cell-line as harboring cells. The $\mathrm{CC}_{50}$ of each drug based on $\mathrm{OD}$ was assessed (Table 2).

Based on the cytotoxicity analysis, no toxic effect was observed in all drugs at concentrations of 12.5, 25, 50, 100, and
$200 \mu \mathrm{g} / \mathrm{ml}$ and as such, the drugs were used in next steps.

\section{Leishmanicidal effects on extra-cellular promastigotes}

The inhibitory activity demonstrated a dose-dependent pattern (Figs. 2, 3). All drugs inhibited the growth of promastigotes effectively; however, selenium plus glucantime niosome showed a higher inhibitory effect (Fig. 2). The $\mathrm{IC}_{50}$ values of selenium and selenium niosome were $78.07 \pm 5$ and $48.2 \pm 6.2$ $\mathrm{\mu g} / \mathrm{ml}$, respectively. Also, the $\mathrm{IC}_{50}$ values of selenium plus glucantime niosome and glucantime plus selenium niosome were $16.11 \pm 0.99$ and $42.17 \pm 2.47 \mu \mathrm{g} / \mathrm{ml}$, respectively. All the drugs showed a good inhibition index against the growth rate of promastigotes, but selenium plus glucantime niosome formulation was the best $(P<0.05)$.

\section{Leishmanicidal effects on intra-cellular amstigotes}

The mean number of intracellular amastigotes in each macrophage, which were treated with drugs and niosomal formulation, was evaluated. Selenium and selenium niosome signifi-
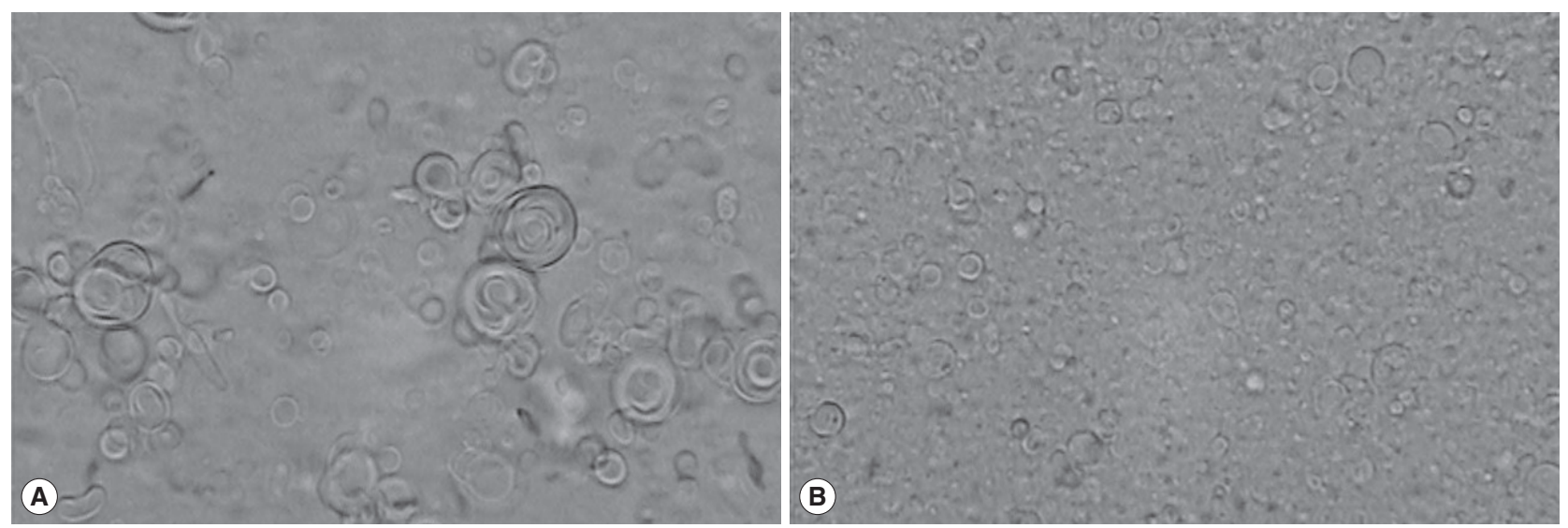

Fig. 1. Microscopic images of Span/Tween 40 (molar ratio=5:5) selenium niosome (A), and Span/Tween 40 (molar ratio=5:5) selenium plus glucantime niosome (B).

Table 2. Comparison of the $\mathrm{IC}_{50}$ values of selenium, selenium niosome, glucantime, glucantime plus selenium niosome and selenium plus glucantime niosome on Leishmania tropica promastigotes and amastigotes, $\mathrm{CC}_{50}$ values of drugs on macrophage and SI index

\begin{tabular}{|c|c|c|c|c|c|c|}
\hline \multirow{2}{*}{ Drug } & \multicolumn{2}{|c|}{ Amastigote } & \multicolumn{2}{|c|}{ Promastigote } & \multirow{2}{*}{$\begin{array}{l}\text { Macrophage } \\
\text { CC }_{50}(\mu \mathrm{g} / \mathrm{ml}) \\
\end{array}$} & \multirow{2}{*}{$\frac{\text { SI }}{\text { (Selectivity Index) }}$} \\
\hline & $\mathrm{IC}_{50 \pm} \mathrm{SD}(\mu \mathrm{g} / \mathrm{ml})$ & $P$-value & $\mathrm{IC}_{50} \pm \mathrm{SD}(\mu \mathrm{g} / \mathrm{ml})$ & $P$-value & & \\
\hline Glucantime & $222.31 \pm 28.04$ & $\leq 0.001$ & $144.5 \pm 97.3$ & $\leq 0.001$ & 1634 & 7.35 \\
\hline Selenium & $216.18 \pm 2.82$ & $\leq 0.001$ & $78.07 \pm 5$ & $\leq 0.001$ & 260.51 & 1.2 \\
\hline Selenium niosome & $78.45 \pm 1.3$ & $\leq 0.001$ & $48.2 \pm 6.2$ & $\leq 0.001$ & 1202 & 15.32 \\
\hline Selenium plus glucantime niosome & $8.67 \pm 0.1$ & $\leq 0.001$ & $16.11 \pm 0.99$ & $\leq 0.001$ & 1105 & 127.45 \\
\hline Glucantime plus selenium niosome & $14.47 \pm 2.22$ & $\leq 0.001$ & $42.17 \pm 2.47$ & $\leq 0.001$ & 1511 & 104.42 \\
\hline
\end{tabular}

$\mathrm{IC}_{50}$, Concentration of drug that caused $50 \%$ of growth inhibition of promastigotes and amastigotes; $\mathrm{CC}_{50}$, Concentration of drug that caused $50 \%$ of cytotoxicity on macrophages; SI (Selectivity index), the ratio between $\mathrm{CC}_{50}$ on $\mathrm{J} 774$ cells and $\mathrm{IC}_{50}$ against $L$. tropica amastigotes $\left(\mathrm{SI}=\mathrm{CC}_{50} / \mathrm{IC}_{50} \geq 10\right.$ non-toxic). 
cantly decreased the mean number of amastigotes in each macrophage as compared with the glucantime or untreated control (Table 3). Various concentrations of combined niosomal formulation were able to significantly inhibit the number of intracellular amastigotes in macrophages as compared

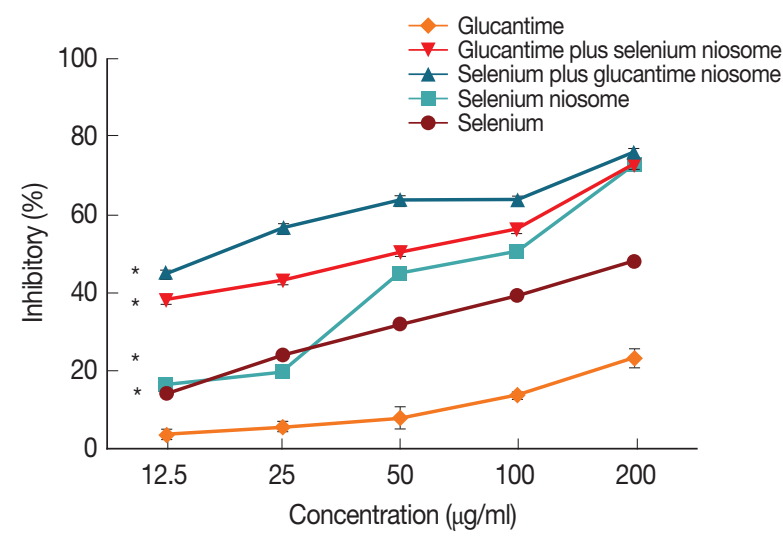

Fig. 2. Comparison of inhibitory effect selenium, selenium niosome, selenium plus glucantime niosome and glucantime plus selenium niosome, on Leishmania tropica promastigotes with glucantime as a standard drug, by MTT assay $\left({ }^{\star} P<0.05\right)$.

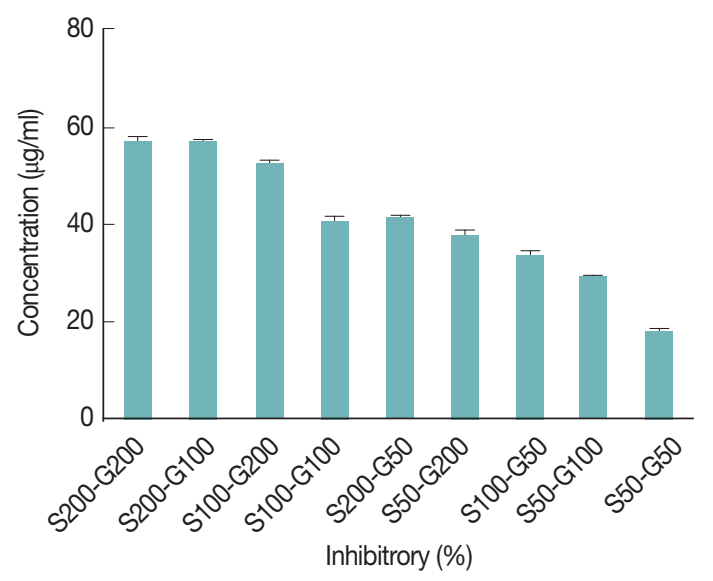

Fig. 3. Inhibitory effect of selenium plus glucantime on promastigotes of Leishmania tropica. with the untreated control $(P<0.001)$ (Table 3).

As regard the effect of all drugs, selenium plus glucantime niosome was significantly more effective than selenium in simple or in combination with Glucantime (Table 4) and the $\mathrm{IC}_{50}$ of this formulation against amastigotes was $8.67 \mu \mathrm{g} / \mathrm{ml}$ $(P<0.001)$ (Table 2).

\section{Real time}

The results of this study showed that the peak of IL-10, as a measure of Th-2, was significantly decreased $(P<0.001)$, although the levels of IL-12 and metacaspase were increased $(P<0.001)$ from concentration of 12.5 to $200 \mu \mathrm{g} / \mathrm{ml}$ (Fig. 4).

\section{DISCUSSION}

Antimonials are used as the first line of CL treatment due to their moderate side effects and painful injection [23]. So far, no effective topical drugs have been found to be useful in the treatment of $\mathrm{CL}$, because intracellular parasites live in the macrophage in the deep layer of derm and as such, it is difficult to

Table 4. Comparison of the overall mean effect of various concentrations of selenium plus glucantime on the mean number of amastigotes in each macrophage

\begin{tabular}{lcc}
\hline \multirow{2}{*}{ Concentrations $(\mu \mathrm{g} / \mathrm{ml})$} & \multicolumn{2}{c}{ Glucantime plus selenium } \\
\cline { 2 - 3 } & Mean $\pm \mathrm{SD}$ & $P$-value \\
\hline 0 (Untreated control) & $36 \pm 0.38$ & $\mathrm{NR}$ \\
$50+50$ & $20.4 \pm 0.4$ & $\leq 0.001$ \\
$50+100$ & $19.76 \pm 0.45$ & $\leq 0.001$ \\
$50+200$ & $18.01 \pm 0.4$ & $\leq 0.001$ \\
$100+50$ & $19.7 \pm 0.3$ & $\leq 0.001$ \\
$100+100$ & $17.2 \pm 0.37$ & $\leq 0.001$ \\
$100+200$ & $13.7 \pm 0.46$ & $\leq 0.001$ \\
$200+50$ & $17.07 \pm 0.31$ & $\leq 0.001$ \\
$200+100$ & $16.2 \pm 0.41$ & $\leq 0.001$ \\
$200+200$ & $13.67 \pm 0.5$ & $\leq 0.001$ \\
\hline
\end{tabular}

Table 3. Comparison of the overall mean effect of various concentrations of selenium, selenium niosome and, glucantime, selenium plus glucantime niosome, and glucantime plus selenium niosome on the mean number of amastigotes in macrophage

\begin{tabular}{|c|c|c|c|c|c|c|c|c|c|c|}
\hline \multirow{2}{*}{$\begin{array}{l}\text { Concentration } \\
(\mu \mathrm{g} / \mathrm{ml})\end{array}$} & \multicolumn{2}{|c|}{ Glucantime } & \multicolumn{2}{|c|}{ Selenium } & \multicolumn{2}{|c|}{ Selenium niosome } & \multicolumn{2}{|c|}{$\begin{array}{l}\text { Selenium plus } \\
\text { glucantime niosome }\end{array}$} & \multicolumn{2}{|c|}{$\begin{array}{l}\text { Glucantime plus } \\
\text { selenium niosome }\end{array}$} \\
\hline & Mean \pm SD & $P$-value & Mean \pm SD & $P$-value & Mean \pm SD & $P$-value & Mean \pm SD & $P$-value & Mean \pm SD & $P$-value \\
\hline 0 (Untreated control) & $22 \pm 1$ & NR & $22 \pm 0.1$ & NR & $22 \pm 1$ & $N R$ & $32 \pm 0.56$ & NR & $32 \pm 0.56$ & NR \\
\hline 12.5 & $21 \pm 0.26$ & 0.51 & $14.7 \pm 0.1$ & $\leq 0.001$ & $15 \pm 0.2$ & $\leq 0.001$ & $13.95 \pm 0.13$ & $\leq 0.001$ & $15.9 \pm 0.38$ & $\leq 0.001$ \\
\hline 25 & $20 \pm 0.75$ & 0.51 & $13.03 \pm 0.12$ & $\leq 0.001$ & $13 \pm 0.7$ & $\leq 0.001$ & $13 \pm 0.1$ & $\leq 0.001$ & $13.84 \pm 0.63$ & $\leq 0.001$ \\
\hline 50 & $15 \pm 0.17$ & $\leq 0.001$ & $12.37 \pm 0.21$ & $\leq 0.001$ & $10 \pm 0.2$ & $\leq 0.001$ & $12.95 \pm 0.05$ & $\leq 0.001$ & $12.85 \pm 0.27$ & $\leq 0.001$ \\
\hline 100 & $12 \pm 0.26$ & $\leq 0.001$ & $11.56 \pm 0.52$ & $\leq 0.001$ & $9 \pm 0.05$ & $\leq 0.001$ & $11.06 \pm 0.19$ & $\leq 0.001$ & $10.83 \pm 0.35$ & $\leq 0.001$ \\
\hline 200 & $10 \pm 0.62$ & $\leq 0.001$ & $8.03 \pm 0.14$ & $\leq 0.001$ & $8 \pm 0.7$ & $\leq 0.001$ & $6.32 \pm 0.25$ & $\leq 0.001$ & $6.45 \pm 0.14$ & $\leq 0.001$ \\
\hline
\end{tabular}



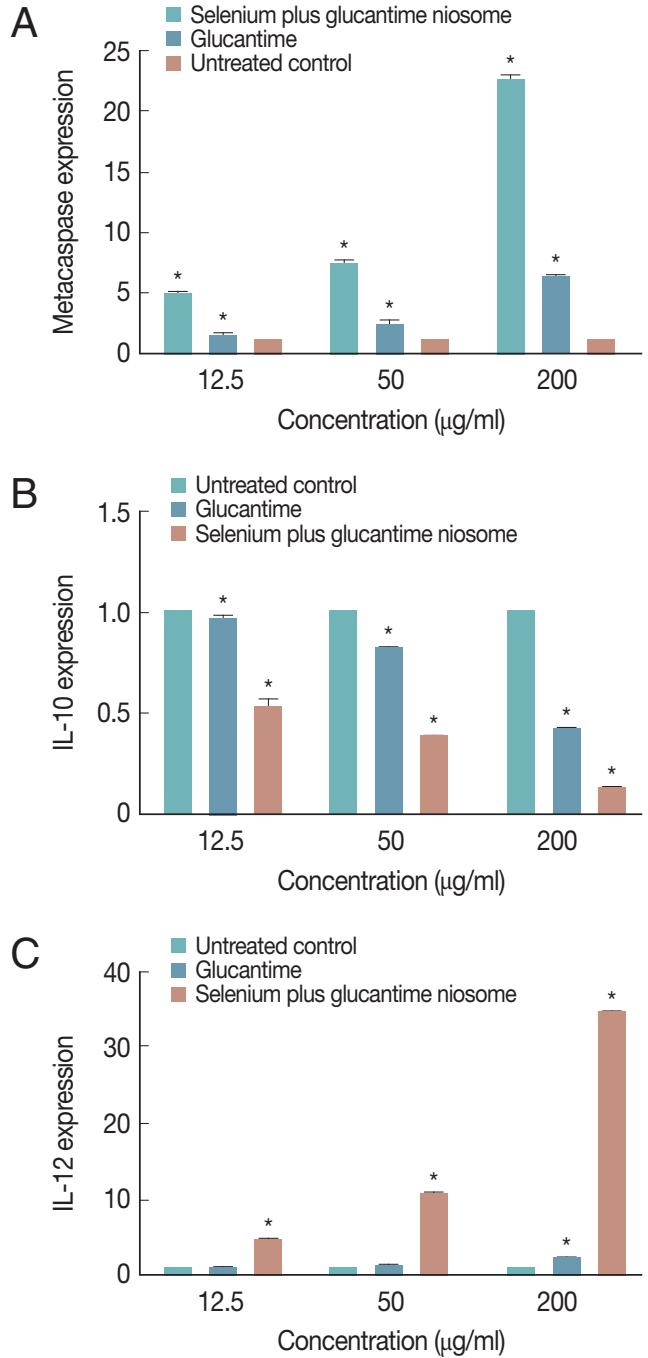

Fig. 4. The gene expression profiles of $(A)$ metacaspase, $(B) I L-$ 10, and (C) IL-12p40 on the Leishmania tropica treated by the selenium plus glucantime niosome and glucantime in comparison with untreated control $\left({ }^{\star} P<0.001\right)$ as measured by using realtime PCR.

access the amastigotes [24].

Therefore, the use of novel delivering of drugs, which is controlled and targeted, is considered to be an effective approach. The application of niosomes and liposomes acting as drug delivery, would be loaded with different drugs. These delivering can control the release drug to the target sites and protect drug from degradation [25]. Niosomes, as compared with liposomes, are more stable chemically and have long half-life during storage [18].

However, small amounts of selenium are required for parasites such as Leishmania and Trypanosoma [26] but high concentration of this could be toxic and can cause biochemical and morphological changes such as DNA fragmentation in promastigotes form of Leishmania. One of the most important changes that occur in programmed cell death is DNA fragmentation [27].

In this study, selenium niosome, selenium plus glucantime niosome or glucantime plus selenium showed lower cytotoxicity as compared with selenium alone. This result is in agreement with other previous studies which reported that Se NPs demonstrated low toxicity $[28,29]$. This result also showed that niosomal formulation had the least cytotoxicity because of its targeting delivery of drugs. Hence, we could evaluate the effects of these formulations on the 2 forms of $L$. tropica using in vitro methods.

Several studies reported that Se NPs had significant effects on Leishmania species $[12,13,30,31]$. The results of the present study also showed the anti-leishmanial effects of niosomal formulation of selenium along with glucantime. The $\mathrm{IC}_{50}$ values indicated that selenium coupled with glucantime niosome were the most effective formulation against both extra- and intracellular stages of L.tropica with the highest safety index (SI = 127) and inhibitory level. As regard the evaluation of SI, niosomal formulation was significantly more active against 2 forms of L.tropica rather than glucantime and selenium as simple forms.

Combination therapy is the best strategy to prevent drug resistance and also enhance efficacy rate against CL. Other advantages of combination therapy are reduction in the length of treatment, in the administration of doses, side effects and cost [32]. In this study, the niosomal combination of selenium plus glucantime was the most effective on L. tropica. Also, other studies have confirmed that combination therapies with meglumine antiminiate along with different drugs, such as terbinafine, imiquimod, allopurinol or verapamil could potentiate synergistic effects in the treatment of CL [33-35].

Th1 (Interferon- $\gamma$, tumor necrosis factor- $\alpha$, IL-12, and nitric oxide) and Th2 (IL-4, IL-10, IL-13, and transforming growth factor- $\beta$ ) are 2 different immune response in Leishmania infection $[36,37]$. In the present study, selenium plus glucantime niosome showed an immunomodulatory role for the inhibition of IL-10 and induction of IL-12, which is indicative of an immunomodulatory role of this formulation in cell death as another possible mechanism of action exerted by this combination. Previous studies have shown that the progression of diseases is correlated with IL-10 which played a potent immunosuppressive activity in leishmaniasis, such as suppression of 
macrophage activation [38]; the biological processes leading to cell death are multifactorial. Cell death process in protozoa, plants, and fungi is due to the expression of metacaspase as cysteine peptidases [39].

The metacaspase in L. major and L. donovani plays an important role in the programmed cell death pathways [39-42].

The results of the present study showed that metacaspase was increased in promastigote form of $L$. tropica treated with selenium plus glucantime niosome. Also, increasing the expression level of metacaspase gene contributed to apoptosis in this parasite, and these findings obtained during the study are in line with the results of previous study [41].

The results of the present study showed that selenium niosome possesses a powerful anti-leishmanial effect and enhanced potent lethal activity especially in combination with glucantime in niosomal form as evidenced by the in vitro experiments. Selenium plus glucantime niosome inhibited Th-2 cytokine, induced the Th-1 cytokine mediators and stimulated an immunomodulatory role against the different stages of $L$. tropica. Such progression of lethal action in in vitro model would be prerequisite for performing further investigation in clinical settings.

\section{ACKNOWLEDGMENTS}

This project (protocol no. 94/691) was granted approval by the Leishmaniasis Research Center and received financial support from the Vice Chancellor for Research at the Kerman University of Medical Sciences. This study is a part of a PhD dissertation for pursuit of a Ph.D by Research degree in Leishmaniasis and skin diseases.

\section{CONFLICT OF INTEREST}

The authors have no conflicts of interest.

\section{REFERENCES}

1. Alvar J, Vélez ID, Bern C, Herrero M, Desjeux P, Cano J, Jannin J, den Boer M. Leishmaniasis worldwide and global estimates of its incidence. PLoS One 2012; 7: e35671.

2. Alvar J, Yactayo S, Bern C. Leishmaniasis and poverty. Trends Parasitol 2006; 22: 552-557.

3. Karimi A, Hanafi-Bojd AA, Yaghoobi-Ershadi MR, Akhavan AA, Ghezelbash Z. Spatial and temporal distributions of phlebotomine sand flies (Diptera: Psychodidae), vectors of leishmaniasis, in Iran. Acta Trop 2014; 132: 131-139.

4. Aflatoonian MR, Sharifi I, Hakimi Parizi M, Fekri AR, Aflatoonian B, Sharifi M, Khosravi A, Khamesipour A, Sharifi H. A prospective cohort study of cutaneous leishmaniasis risk and opium addiction in south eastern Iran. PLoS One 2014; 9: e89043.

5. Sharifi I, Aflatoonian MR, Fekri AR, Hakimi Parizi M, Aghaei Afshar A, Khosravi A, Sharifi F, Aflatoonian B, Khamesipour A, Dowlati Y, Modabber F, Nadim A. A comprehensive review of cutaneous leishmaniasis in kerman province, southeastern irannarrative review article. Iran J Public Health 2015; 44: 299-307.

6. Saghafipour A, Rassi Y, Abai MR, Oshaghi MA, Farzinnia B, Mostafavi R, Karimian F. Outbreak of zoonotic cutaneous leishmaniasis: a report. Arch Hyg Sci 2013; 2: 48-54.

7. Torrado JJ, Espada R, Ballesteros MP, Torrado-Santiago S. Amphotericin B formulations and drug targeting. J Pharm Sci 2008; 97: 2405-2425.

8. Eddaikra N, Ait-Oudhia K, Kherrachi I, Oury B, Moulti-Mati F, Benikhlef R, Harrat Z, Sereno D. Antimony susceptibility of Leishmania isolates collected over a 30-year period in Algeria. PLoS Negl Trop Dis 2018; 12: e0006310.

9. Mishra J, Saxena A, Singh S. Chemotherapy of leishmaniasis: past, present and future. Curr Med Chem 2007; 14: 1153-1169.

10. Rayman MP. Selenium and human health. Lancet 2012; 379: 1256-1268.

11. Tapiero H, Townsend DM, Tew KD. The antioxidant role of selenium and seleno-compounds. Biomed Pharmacother 2003; 57: 134-144.

12. Mahmoudvand H, Shakibaie M, Tavakoli R, Jahanbakhsh S, Sharifi I. In vitro study of leishmanicidal activity of biogenic selenium nanoparticles against Iranian isolate of sensitive and glucantime-resistant Leishmania tropica. Iran J Parasitol 2014; 9: 452460.

13. Beheshti N, Soflaei S, Shakibaie M, Yazdi MH, Ghaffarifar F, Dalimi A, Shahverdi AR. Efficacy of biogenic selenium nanoparticles against Leishmania major: In vitro and in vivo studies. J Trace Elem Med Biol 2013; 27: 203-207.

14. Soflaei S, Dalimi A, Abdoli A, Kamali M, Nasiri V, Shakibaie M, Tat M. Anti-leishmanial activities of selenium nanoparticles and selenium dioxide on Leishmania infantum. Comp Clin Path 2014; 23: $15-20$.

15. Debnath A, Kumar A. Structural and Functional significance of Niosome and Proniosome in Drug Delivery System. Int J Pharm and Eng 2015; 3: 621-637.

16. Mahale NB, Thakkar PD, Mali RG, Walunj DR, Chaudhari SR. Niosomes: novel sustained release nonionic stable vesicular systems - an overview. Adv Colloid Interface Sci 2012; 183: 46-54.

17. Riabi TR, Sharifi I, Miramin Mohammadi A, Khamesipour A, Hakimi Parizi M. Evaluation of a possible synergistic effect of meglumine antimoniate with paromomycin, miltefosine or allopurinol on in vitro susceptibility of Leishmania tropica resistant isolate. Iran J Parasitol 2013; 8: 396-401.

18. Uchegbu IF, Florence AT. Non-ionic surfactant vesicles (niosomes): physical and pharmaceutical chemistry. Adv Colloid In- 
terface Sci 1995; 58: 1-55.

19. Koutsoni O, Barhoumi M, Guizani I, Dotsika E. Leishmania eukaryotic initiation factor (LeIF) inhibits parasite growth in murine macrophages. PLoS One 2014; 9: e97319.

20. Chandra D, Naik S. Leishmania donovani infection down-regulates TLR2-stimulated IL-12p40 and activates IL-10 in cells of macrophage/monocytic lineage by modulating MAPK pathways through a contact-dependent mechanism. Clin Exp Immunol 2008; 154: 224-234.

21. Zhong M, Wang X, Wen J, Cai J, Wu C, Aly SM. Selection of reference genes for quantitative gene expression studies in the house fly (Musca domestica L.) using reverse transcription quantitative real-time PCR. Acta Biochim Biophys Sin (Shanghai) 2013; 45: 1069-1073.

22. S SK, R K G, Ghosh M. Comparative in-silico genome analysis of Leishmania (Leishmania) donovani: a step towards its species specificity. Meta gene 2014; 2: 782-798.

23. Kalat SA, Khamesipour A, Bavarsad N, Fallah M, Khashayarmanesh Z, Feizi E, Neghabi K, Abbasi A, Jaafari MR. Use of topical liposomes containing meglumine antimoniate (Glucantime) for the treatment of L. major lesion in BALB/c mice. Exp Parasitol 2014; 143: 5-10.

24. Ag Seleci D, Seleci M, Walter JG, Stahl F, Scheper T. Niosomes as nanoparticular drug carriers: fundamentals and recent applications. J Nanomater 2016; 2016: 1-13.

25. Lobanov A V, Gromer S, Salinas G, Gladyshev VN. Selenium metabolism in Trypanosoma: characterization of selenoproteomes and identification of a Kinetoplastida-specific selenoprotein. Nucleic Acids Res 2006; 34: 4012-4024.

26. Wlodkowic D, Telford W, Skommer J, Darzynkiewicz Z. Apoptosis and beyond: cytometry in studies of programmed cell death. Methods Cell Biol 2011; 103: 55-98.

27. Zhang J, Wang H, Yan X, Zhang L. Comparison of short-term toxicity between Nano-Se and selenite in mice. Life Sci 2005; 76: 1099-1109.

28. Wang H, Zhang J, Yu H. Elemental selenium at nano size possesses lower toxicity without compromising the fundamental effect on selenoenzymes: Comparison with selenomethionine in mice. Free Radic Biol Med 2007; 42: 1524-1533.

29. de Souza CES, da Silva ARP, Gomez MCV, Rolóm M, Coronel C, da Costa JGM, Sousa AK, Rolim LA, de Souza FHS, Coutinho HDM. Anti-Trypanosoma, anti-Leishmania and cytotoxic activities of natural products from Psidium brownianum Mart. ex DC. and Psidium guajava var. Pomifera analysed by LC-MS. Acta Trop 2017; 176: 380-384.

30. Martín-Montes Á, Plano D, Martín-Escolano R, Alcolea V, Díaz M, Pérez-Silanes S, Espuelas S, Moreno E, Marín C, GutiérrezSánchez R, Sanmartín C, Sánchez-Moreno M. Library of seleno- compounds as novel agents against Leishmania species. Antimicrob Agents Chemother 2017; 61: 1-13.

31. Olliaro PL. Drug combinations for visceral leishmaniasis. Curr Opin Infect Dis 2010; 23: 595-602.

32. Firooz A, Khamesipour A, Ghoorchi MH, Nassiri-Kashani M, Eskandari SE, Khatami A, Hooshmand B, Gorouhi F, RashighiFiroozabadi M, Dowlati Y. Imiquimod in combination with meglumine antimoniate for cutaneous leishmaniasis: a randomized assessor-blind controlled trial. Arch Dermatol 2006; 142: 1575-1579.

33. Shamsi Meymandi S, Javadi A, Dabiri S, Shamsi Meymandi M, Nadji M. Comparative histological and immunohistochemical changes of dry type cutaneous leishmaniasis after administration of meglumine antimoniate, imiquimod or combination therapy. Arch Iran Med 2011; 14: 238-243.

34. Farajzadeh S, Esfandiarpour I, Haghdoost AA, Mohammadi S, Mohebbi A, Mohebbi E4, Mostafavi M1. Comparison between combination therapy of oral terbinafine and cryotherapy versus systemic meglumine antimoniate and cryotherapy in cutaneous leishmaniasis: a randomized clinical trial. Iran J Parasitol 2015; 10: 1-8.

35. Gannavaram S, Bhattacharya P, Ismail N, Kaul A, Singh R, Nakhasi HL. Modulation of innate immune mechanisms to enhance leishmania vaccine-induced immunity: role of coinhibitory molecules. Front Immunol 2016; 7: 187.

36. Prajapati VK, Awasthi K, Gautam S, Yadav TP, Rai M, Srivastava ON, Sundar S. Targeted killing of Leishmania donovani in vivo and in vitro with amphotericin $\mathrm{B}$ attached to functionalized carbon nanotubes. J Antimicrob Chemother 2011; 66: 874-879.

37. Bogdan BC, Vodovotz Y, Nathan C. Macrophage deactivation by interleukln 10. J Exp Med 1991; 174: 1549-1555.

38. Ambit A, Fasel N, Coombs GH, Mottram JC. An essential role for the Leishmania major metacaspase in cell cycle progression. Cell Death Differ 2008; 15: 113-122.

39. Raina P, Kaur S. Knockdown of LdMC1 and Hsp70 by antisense oligonucleotides causes cell-cycle defects and programmed cell death in Leishmania donovani. Mol Cell Biochem 2012; 359: 135-149.

40. Lee N, Bertholet S, Debrabant A, Muller J, Duncan R, Nakhasi HL. Programmed cell death in the unicellular protozoan parasite Leishmania. Cell Death Differ 2002; 9: 53-64.

41. Zalila H, González IJ, El-Fadili AK, Delgado MB, Desponds C, Schaff C, Fasel N. Processing of metacaspase into a cytoplasmic catalytic domain mediating cell death in Leishmania major. Mol Microbiol 2011; 79: 222-239.

42. Debrabant A, Lee N, Bertholet S, Duncan R, Nakhasi HL. Programmed cell death in trypanosomatids and other unicellular organisms. Int J Parasitol 2003; 33: 257-267. 